\title{
Diets enriched with whole grains reduce premenstrual syndrome scores in nurses: an open-label parallel randomised controlled trial
}

\author{
Mozhgan Esmaeilpour ${ }^{1}$, Sedigheh Ghasemian ${ }^{2}$ and Mohammad Alizadeh ${ }^{3 *}$ \\ ${ }^{1}$ Student Research Committee, Department of Nutrition, School of Medicine, Urmia University of Medical Sciences, PO Box \\ 5756115111, Serow Highway, Nazloo, Urmia, Iran \\ ${ }^{2}$ Department of Obstetrics and Gynecology, School of Medicine, Urmia University of Medical Sciences, PO Box 5756115111, \\ Serow Highway, Nazloo, Urmia, Iran \\ ${ }^{3}$ Department of Nutrition, Food and Beverages Safety Research Center, School of Medicine, Urmia University of Medical \\ Sciences, PO Box 5756115111, Serow Highway, Nazloo, Urmia, Iran
}

(Submitted 11 December 2018 - Final revision received 20 January 2019 - Accepted 4 February 2019 - First published online 05 April 2019)

\section{Abstract}

Although previous studies have demonstrated the beneficial effects of some components of whole grains on premenstrual syndrome (PMS), our literature review shows that no clinical trial has studied the effect of whole grain consumption on PMS so far. Therefore, the present study was designed to study the effect of diets rich in whole grains on PMS among nurses. This study is a parallel controlled clinical trial with a 3-month intervention period in which, after following two menstrual cycles among nurses, 100 nurses diagnosed with PMS were randomly divided into two groups of intervention and control, with fifty individuals in each. Those in the intervention group replaced at least four servings of refined grains in their daily diets with whole grains. To supply four servings, $120 \mathrm{~g}$ of bread made with whole flour was given to the intervention group on a daily basis. Those in the control group, however, continued their regular daily consumption of grains. The two groups were compared regarding PMS symptoms after adjusting the confounding variables. The repeated measurement test showed that the interaction between the time factor and the experimental group on the mean score of PMS symptoms was significant. That is, the intervention group showed a significant decrease in the general, mood, physical and behavioural symptoms of PMS compared with the controls $(P<0 \cdot 001$, $P=0.01, P<0.001$ and $P=0.003$, respectively). Therefore, daily consumption of whole grains in place of refined grains can contribute to improvement in PMS symptoms. Further studies are needed to confirm our findings.

\section{Key words: Premenstrual syndrome: Whole grains: Randomised controlled trials: Nurses}

Premenstrual syndrome (PMS) is one of the most common disorders among women of reproductive age and has a negative impact on their quality of life $e^{(1)}$. This syndrome is characterised by a set of physical, mood and behavioural symptoms ${ }^{(2)}$, such as headache, backache, breast tenderness, anxiety, depression, irritability, fatigue, change in appetite and insomnia ${ }^{(3)}$, which usually starts in the luteal phase of menstrual cycle and disappears shortly after the onset of menstruation flow ${ }^{(2)}$. The worldwide prevalence of this syndrome is reported to be 13$18 \%{ }^{(4)}$ and $54.9 \%$ among Iranian women ${ }^{(5)}$. Among women of different jobs, nurses are the ones mostly affected ${ }^{(6)}$. The precise aetiology of PMS is not completely clear yet; however, hypotheses such as hormonal changes, hypoglycaemia and nutritional deficiencies are being considered. The main goal of PMS treatment is controlling its symptoms and allowing the individual to have a proper performance during her menstrual cycle. Recently, using selective serotonin reuptake inhibitors (SSRI) has been the dominant treatment of this syndrome; however, side effects such as insomnia, anxiety and decreased libido have been reported ${ }^{(7)}$. For this reason, controlling the symptoms of this syndrome using safe methods such as nutritional interventions can be of value ${ }^{(8)}$.

Whole-grain foods constitute one of the valuable foods that its three main components, namely, germ, bran and endosperm, in contrast to refined grains, remain in it and are rich in dietary fibres, vitamin $\mathrm{B}, \mathrm{Fe}, \mathrm{Mg}$ and vitamin $\mathrm{E}^{(9)}$. In several studies, a daily consumption of $16-48 \mathrm{~g}$ of whole grains was related to receiving more sufficient amounts of vitamins and minerals $^{(10-13)}$. In some studies, consumption of components of whole grains including vitamins $\mathrm{B}_{1}, \mathrm{~B}_{6}$ and $\mathrm{D}, \mathrm{Ca}, \mathrm{Zn}$ and $\mathrm{Mg}$, as dietary supplements caused the relief of some PMS symptoms ${ }^{(14-18)}$, and a positive relationship was reported between dietary B vitamins and the risk of PMS ${ }^{(19)}$. Supplementation of wheat germ extract reduced physical and psychological symptoms ${ }^{(20)}$. Furthermore, Western dietary

Abbreviations: BFM, body fat mass; DSR, daily symptom record; PMS, premenstrual syndrome.

* Corresponding author: M. Alizadeh, fax +98 4432780800, email alizade85@yahoo.com, alizadeh.m@umsu.ac.ir 
patterns that included refined grains increased the odds of $\mathrm{PMS}^{(21)}$, and healthy dietary patterns had beneficial effects on PMS management ${ }^{(22)}$.

Considering the high prevalence of PMS among women and the side effects of the common treatments, there is an apparent need for studying treatments with fewer side effects. For this reason, relieving the severity of PMS symptoms with dietary interventions can prove beneficial. Having access to whole grains is difficult in Iran and the major portion of consumed grains is of refined type, and this increases the chance of vitamin $\mathrm{B}$ and some mineral deficiencies to a high extent ${ }^{(23)}$. Despite the beneficial effects of some components of whole grains including vitamin $\mathrm{B}$ and some minerals being shown by previous studies, to the best of our knowledge, no clinical trial regarding the effect of whole grain consumption on PMS has been conducted; consequently, this study was designed with the aim of investigating the effect of a diet rich in whole grains on PMS among nurses.

\section{Methods}

\section{Subjects}

The participants of this study consisted of volunteered female nurses whose age ranged from 18 to 45 years and who were working at Urmia hospitals. All nurses from all sections (except from the operating rooms) of all hospitals of Urmia city (except for two hospitals due to their own failure to enter) including seven private and state hospitals on different days and different working shifts were interviewed face-to-face from October 2016 to February 2017, regarding PMS symptoms. From among all the interviewed nurses, 232 whose probability of PMS was high and announced their readiness to participate in the study were included; however, there were sixteen nurses meeting the exclusion criteria and were, consequently, excluded. The exclusion criteria consisted of having any illness affecting PMS symptoms including mental or psychological diseases and any diagnosed clinical condition such as cancer, CVD, renal, hepatic, neurological, infectious and endocrine diseases; surgery during the last 6 months; use of hormones and contraceptives to relieve symptoms; being treated with methods such as acupuncture, homeopathy, and other complementary medical treatments; following a weight loss diet, doing regular exercise, a BMI $>39 \mathrm{~kg} / \mathrm{m}^{2}$, smoking, alcohol consumption, use of medication; death of a close relative and other stressful events over the last 6 months; breast-feeding and pregnancy. Considering the symptoms common between PMS and depression, to ensure of the remaining nurses ( $n$ 216) not being severely depressed, the volunteers completed the valid and reliable Beck questionnaire $^{(24)}$ and those whose scores were above 16 were excluded from the study ( $n$ 33). Next, the remaining individuals ( $n$ 183) were evaluated in terms of inclusion criteria. The criteria consisted of having PMS, an age between 18 and 45 years, regular menstrual cycles of 21-35 d and menstrual bleeding between 3 and $8 \mathrm{~d}$. Daily symptom record (DSR) questionnaires were used to diagnose PMS. The participants were asked to enter the symptoms of their two consecutive menstrual cycles in the questionnaire on a daily basis. The participants were kept in touch by telephone during these 2 months.
PMS diagnosis was carried out based on the diagnosis criteria of the American College of Obstetricians and Gynecologists ${ }^{(25)}$, that is, reporting at least one of the following symptoms during their two consecutive menstrual cycles (prospective recording): depression, anger outburst, irritability, anxiety, confusion, social withdrawal, breast tenderness, abdominal bloating, headache and swelling of extremities. The reported symptoms were supposed to have interfered with the individual's daily life and not to be related to a disease, drug and hormone consumption or any other reason. Moreover, the symptoms were supposed to appear $5 \mathrm{~d}$ before the onset of bleeding and disappear $4 \mathrm{~d}$ after it without recurrence until at least day 13 of the menstrual cycle. During these 2 months of follow-up, some other nurses ( $n$ 70) were excluded from the study due to various reasons, such as going on a weight loss diet, committing errors in filling out the questionnaire (mistakes in completing the DSR questionnaire such as frequent mistakes in entering the score of symptoms in the appropriate day of the menstrual cycle), losing the questionnaire and unwillingness to continue participation in the study. Since in the first face-to-face meeting, the existence of several of the menstrual symptoms in the participants was made sure of; after the end of 2 months of follow-up, only a small number of the nurses ( $n$ 13) were excluded for not contracting PMS and eventually 100 nurses were diagnosed with PMS and were included in the study.

\section{Ethics approval}

This study was carried out based on Helsinki contract guidelines and approved by ethics committee of Urmia University of Medical Sciences under code IR.REC.UMSU.1395.256 and registered at clinical trial site (http://www.irct.ir) under code IRCT2017031132417N3. In addition, before starting the study, written informed consent was obtained from each of the participants

\section{Design}

This study is a parallel, randomised, controlled, open-label trial with an intervention period of 3 months in which 100 nurses diagnosed with PMS were randomly allocated into two groups of intervention and control with fifty individuals in each. The individuals in the intervention group were asked to replace at least four servings of their daily refined grain consumption with whole grains. They were also given a list of whole-grain food items including whole-wheat bread, brown rice, brown spaghetti, home-made cakes and cookies made using whole-wheat flour instead of refined types and thereby increase their consumption of legumes to choose from. Moreover, the individuals in the intervention group were given $840 \mathrm{~g}$ of whole bread each week, so that they would replace their daily consumption of refined bread with $120 \mathrm{~g}$ of this bread and were asked not to consume refined bread as much as possible. The participants whose daily whole grain consumption was less than four servings ( $n$ 6) were excluded from the study. The intervention and control groups' participants were supposed to fill out DSR questionnaires on a daily basis for three menstrual cycles, in parallel to 3 months of intervention. In addition to filling out DSR questionnaires, anthropometry and body composition 
including weight, BMI, body fat mass (BFM), skeletal muscle mass (SMM), percentage of body fat (PBF), waist:hip ratio (WHR) and visceral fat area (VFA) of the two groups' participants were evaluated before and after intervention using bioelectrical impedance analysis method (InBody 770; InBody Co.).

\section{Assessment of compliance}

The participants from both groups were asked not to change their usual lifestyle, diet and physical activities. To make sure of stability and consistency in implementing and considering the previously mentioned points by the participants, the follow up was carried out via frequent telephone calls and face-to-face meetings in the hospitals the participants were working. Furthermore, they were asked to complete a 3-d food records and metabolic equivalent of task (MET) questionnaire three times, that is, once before the start of intervention then with 1-, 2- and 3-month time gap after the start of the intervention. Necessary instructions were provided to the participants thoroughly both as written and as face-to-face. They were instructed to record everything they ate as servings in details in two weekdays and one weekend day. Moreover, to make sure that they received the breads, the participants in the intervention group were given bread coupons and after the end of 1 month, the coupons were collected from the bread distribution centre. Furthermore, to prevent loss of the DSR papers and food records and physical activity questionnaires, the participants sent images of their questionnaires at the end of each month of menstrual cycle to be archived in specified files. The mean of daily consumption of nutrients and food groups in both the intervention and control groups was analysed using Nutrition 4 software (First Databank Inc.; Hearst Corporation) adopted for the Iranian foods. To calculate the MET for each participant, the time $(\mathrm{h} / \mathrm{d})$ reported for each physical activity was multiplied by its relevant MET coefficient.

\section{Daily symptom record}

This questionnaire was introduced by Freeman et al. in 1996 and its validity and reliability have been confirmed ${ }^{(26,27)}$. DSR is a self-report questionnaire and determines the severity of PMS using twenty different symptoms divided into the following three subgroups: mood symptoms (restlessness; irritability; anxiety, depression or sadness; crying; feeling of isolation), physical symptoms (headache, breast tenderness, acne, backache, abdominal pain, weight gain, swelling of extremities, muscle stiffness, gastrointestinal symptoms, nausea) and behavioural symptoms (fatigue, lack of energy, insomnia, difficulty in concentrating, increased or decreased appetite). The severity of symptoms was evaluated as ' 0 ' absence of symptoms, ' 1 ' mild symptoms that may not interfere with daily activities of the person, '2' moderate symptoms that interfere with daily activities of the person and ' 3 ' severe symptoms that hinder the person from performing her daily activities. In this study, to calculate the severity of each symptom, we added the score of symptom during a period of $5 \mathrm{~d}$ before and $4 \mathrm{~d}$ after the 1 st day of menstruation and reported it as the severity of that symptom in that month. To calculate the severity of mood, physical and behavioural symptoms, in a similar manner, we added the scores of symptom subgroups to obtain the severity score. Furthermore, to compare the symptoms before and after the intervention between the groups, we considered the mean severity scores of the symptoms in 2 months before intervention as the baseline and compared them with those of the first, second and third months.

\section{Statistical analysis}

Calculation of the sample size was determined based on the reduction of anxiety scores in the intervention and control groups in a study conducted by Ebrahimi et al. ${ }^{(16)}$, and considering the mean of $12 \cdot 1$ (SD 19) using the following formula: $N=\left(Z_{1}+Z_{2}\right)^{2}\left(S_{1}^{2}+S_{2}^{2}\right) /\left(\mu_{1}-\mu_{2}\right)^{2}$. Since $\alpha$ (type I error) and $\beta$ (type II error) were set at 0.05 and 0.2 , respectively, the sample size was obtained to be 38 .

To evaluate the normality of data distribution, KolmogorovSmirnov statistical test was used. To compare anthropometric variables at the onset and offset of the study, a paired $t$ test was conducted and to compare the changes in the two groups by adjusting the base value of effects, a covariance analysis was performed.

To identify confounding variables, first, the $\chi^{2}$, MannWhitney and repeated-measures tests were applied and then the two groups were compared for some demographic and background variables, physical activity, intake of food groups and macronutrients and changes in anthropometric indices. Those variables with a $P<0.25$ were chosen to enter the final model as covariates. Eventually, to compare the two groups for PMS symptoms, the two-covariance analysis model was applied. In model 1, only the effect of base values was adjusted (the mean scores of PMS symptoms in the two cycles before the intervention be considered the baseline score); and in model 2 , in addition to adjusting the effect of base values, the effects of marital status; age; duration of a menstrual cycle; the mean change of physical activity; intake of energy, protein, carbohydrate and fat across different times during the study; and changes in BMI, BFM, SMM, PBF, WHR were adjusted as well. Highly correlated variables were extracted as factors using factor analysis and then these factors were used as covariates instead of single variables. Therefore, energy, protein and carbohydrate as factor 1 and BMI, BFM and PBF as factor 2 were entered into the model as covariates. The data were analysed using version 22 of SPSS software. In all performed analysis, $P \leq 0.05$ was considered as significant.

\section{Results}

\section{Subject characteristics}

One hundred participants were randomly allocated to the intervention and control groups. Next, six individuals, due to loss of interest in participation in the study; six individuals, due to not following the intervention (consuming less than four servings of whole grains in the intervention group); one individual, due to going under surgery; three individuals, due to following weight loss diets; one individual, due to becoming 
Starting a weight loss diet, committing errors in completing the questionnaires, losing the questionnaires, unwillingness to continue participation in the study $(n 70)$ and not meeting inclusion criteria $(n 13)$

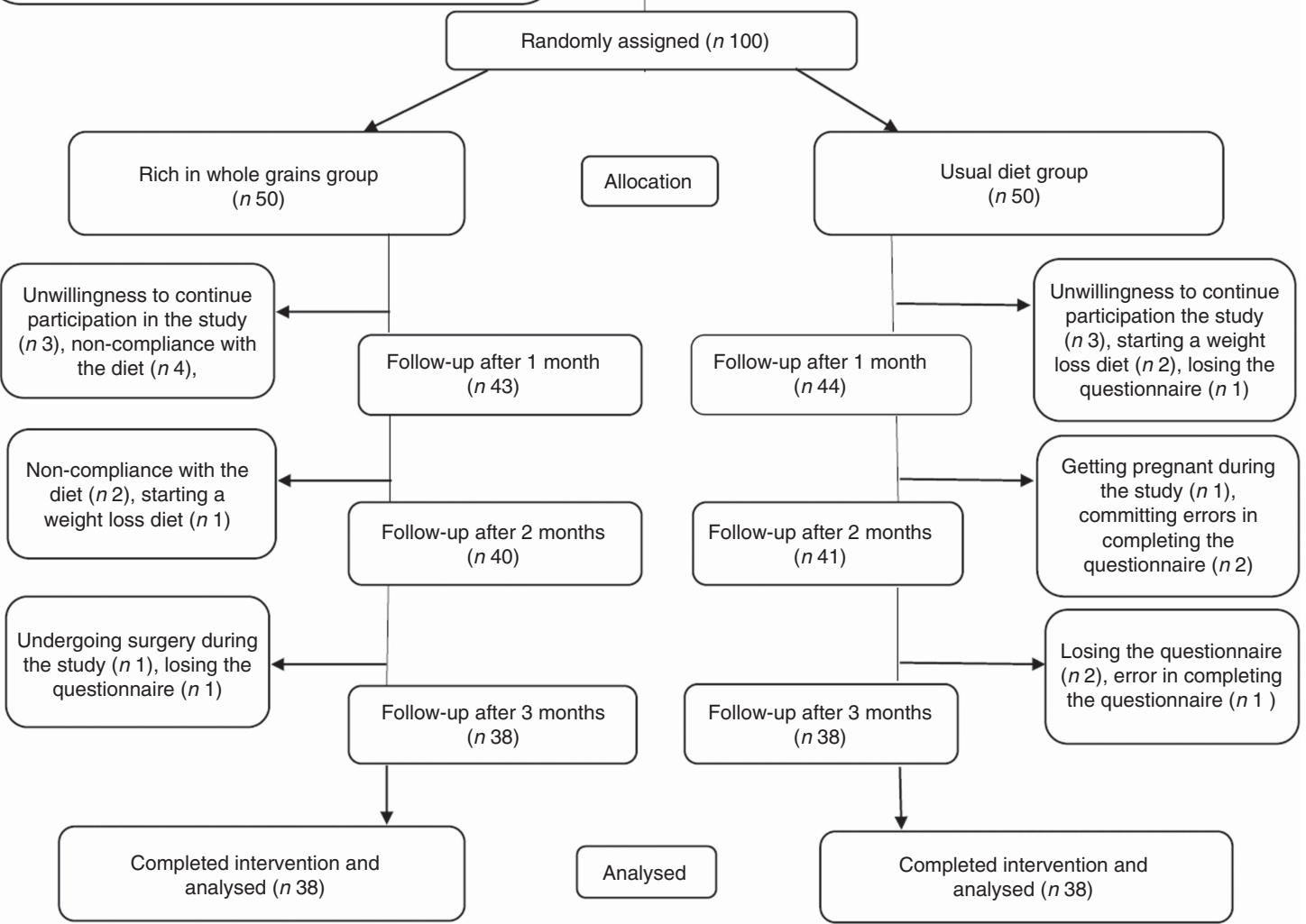

Fig. 1. Participant eligibility, screening, randomisation and follow-up of premenstrual syndrome patients.

pregnant during the course of study; four individuals, due to losing DSR or food record questionnaire; and three individuals, due to committing errors in completing the questionnaires were excluded from the study. Ultimately, seventy-six individuals including thirty-eight in the intervention group and thirty-eight in the control group completed the study (Fig. 1). Results of the $\chi^{2}$ test showed that there were no significant differences between the two groups in baseline characteristics and demographics other than the duration of a menstrual cycle that was longer in the intervention group than that in the control group $(P=0 \cdot 007)$ (Table 1).

\section{Physical activity and nutritional analysis}

Results of covariance analysis (by adjusting the base values effects) showed that there was a significant difference $(P=0.002)$ between the two groups in mean physical activity levels. Physical activity levels of the two experimental groups were compared during the study period (Table 2) and the repeated-measures test showed that the physical activity levels of the individuals had not changed significantly during the study $(P=0.568)$. Consequently, the effect of physical activity was adjusted in the final analysis as the cofounding variable. In Table 2, intake of nutrients and food groups in both the 
Table 1. Comparison between the background and demographics of nurses diagnosed with premenstrual syndrome (PMS)* (Numbers and percentages; medians and ranges)

\begin{tabular}{|c|c|c|c|c|c|}
\hline \multirow[b]{2}{*}{ Variables } & \multicolumn{2}{|c|}{ Rich in whole grain group ( $n 38)$} & \multicolumn{2}{|c|}{ Usual diet group ( $n$ 38) } & \multirow[b]{2}{*}{$P$} \\
\hline & Median & Range & Median & Range & \\
\hline \multicolumn{6}{|l|}{ Marital status } \\
\hline \multicolumn{6}{|l|}{ Single } \\
\hline$n$ & \multirow{2}{*}{\multicolumn{2}{|c|}{$\begin{array}{c}16 \\
42 \cdot 1\end{array}$}} & \multicolumn{2}{|r|}{24} & 0.07 \\
\hline$\%$ & & & & 63.2 & \\
\hline \multicolumn{6}{|l|}{ Married } \\
\hline$n$ & \multicolumn{2}{|c|}{22} & \multicolumn{2}{|r|}{14} & \\
\hline$\%$ & \multicolumn{2}{|c|}{$57 \cdot 9$} & \multicolumn{2}{|c|}{$36 \cdot 8$} & \\
\hline \multicolumn{6}{|l|}{ Consumption of dietary supplements over the last 6 months } \\
\hline \multicolumn{6}{|l|}{ Yes } \\
\hline$n$ & \multirow{2}{*}{\multicolumn{2}{|c|}{$\begin{array}{c}16 \\
42 \cdot 1\end{array}$}} & \multirow{2}{*}{\multicolumn{2}{|c|}{$\begin{array}{c}17 \\
44.7\end{array}$}} & 0.82 \\
\hline$\%$ & & & & & \\
\hline \multicolumn{6}{|l|}{ No } \\
\hline$n$ & \multicolumn{2}{|c|}{22} & \multicolumn{2}{|r|}{21} & \\
\hline$\%$ & \multicolumn{2}{|c|}{$57 \cdot 9$} & \multicolumn{2}{|c|}{$55 \cdot 3$} & \\
\hline \multicolumn{6}{|l|}{ PMS family history } \\
\hline \multicolumn{6}{|l|}{ Yes } \\
\hline$n$ & \multirow{2}{*}{\multicolumn{2}{|c|}{$\begin{array}{c}24 \\
63 \cdot 2\end{array}$}} & \multicolumn{2}{|r|}{19} & 0.25 \\
\hline$\%$ & & & & 50 & \\
\hline \multicolumn{6}{|l|}{ No } \\
\hline$n$ & \multirow{2}{*}{\multicolumn{2}{|c|}{$\begin{array}{c}14 \\
36 \cdot 8\end{array}$}} & \multirow{2}{*}{\multicolumn{2}{|c|}{$\begin{array}{l}19 \\
50\end{array}$}} & \\
\hline$\%$ & & & & & \\
\hline Age (years) & 34.5 & $19-45$ & $27 \cdot 5$ & $19-45$ & 0.13 \\
\hline Age at menarche (years) & 14 & $11-16$ & 13 & $10-16$ & 0.63 \\
\hline Bleeding time (d) & $5 \cdot 5$ & $4-8$ & $5 \cdot 5$ & $3-8$ & 0.82 \\
\hline Duration of menstrual cycle (d) & 28 & $21-35$ & 26 & $21-35$ & 0.01 \\
\hline Weight at the onset of the study $(\mathrm{kg})$ & $62 \cdot 9$ & $42 \cdot 0-84 \cdot 4$ & $62 \cdot 0$ & $45 \cdot 4-88 \cdot 7$ & 0.54 \\
\hline BMI at the onset of the study $\left(\mathrm{kg} / \mathrm{m}^{2}\right)$ & $25 \cdot 6$ & $17 \cdot 5-36 \cdot 2$ & $24 \cdot 6$ & $17 \cdot 8-35 \cdot 6$ & 0.31 \\
\hline Beck depression score at the onset of the study & $7 \cdot 0$ & $0-16$ & $6 \cdot 5$ & $0-16$ & 0.92 \\
\hline Mean general symptoms score of PMS in the first two cycles before intervention & $90 \cdot 2$ & $19 \cdot 5-371$ & $69 \cdot 2$ & $14 \cdot 5-303 \cdot 5$ & 0.07 \\
\hline Mean mood symptoms score of PMS in the first two cycles before intervention & $20 \cdot 7$ & $2-94.5$ & $18 \cdot 0$ & $2-97.5$ & 0.20 \\
\hline Mean physical symptoms score of PMS in the first two cycles before intervention & $42 \cdot 7$ & $10 \cdot 5-192$ & $30 \cdot 0$ & $7-127 \cdot 5$ & 0.06 \\
\hline Mean behavioural symptoms score of PMS in the first two cycles before intervention & $25 \cdot 7$ & $0.5-84.5$ & $18 \cdot 0$ & $0.5-86$ & 0.12 \\
\hline
\end{tabular}

* To compare the qualitative and quantitative variables in the two groups, $x^{2}$ and Mann-Whitney tests were applied, respectively.

intervention and control groups were inserted as separated by time. Based on the results of repeated-measures tests, the interaction of the factor of time and experimental group on the mean intake of niacin was significant $(P=0.036)$; meaning that the difference between the two groups was not constant over time and niacin intake increased in the intervention group and decreased in the control group over time. Based on the results of repeated-measures analysis test, the effect of time factor on the mean intake of energy, pantothenic acid, crude fibre, tryptophan, biotin and fruits was significant; that is, their intake level over the course of time has undergone significant changes $(P<0.05)$. In this study, in both the intervention and control groups, intake of dietary fibre, milk and dairy products, vegetables, cereals, meats and fats were constant over time and did not go under significant changes.

Covariance analysis test (by adjusting the base values) showed significant differences $(P<0.05)$ in consumption of energy, protein, carbohydrate, $\mathrm{Fe}, \mathrm{Mg}, \mathrm{Zn}, \mathrm{Mn}$, vitamin $\mathrm{E}$, thiamine, pantothenic acid, vitamin $\mathrm{K}$, crude fibre, tryptophan, $\mathrm{P}, \mathrm{Cu}$, pyridoxine, biotin, dietary fibre, cereals and fats and that the intake of these nutrients and food groups after adjustment of the base values was higher in the intervention group than that in the control group. The mean of whole grain consumption changed in the control group from 0.59 servings before the start of intervention to $0.71,0.61$ and 0.59 servings in the first, second and third months after the start of intervention, respectively, and it changed in the intervention group from 0.94 servings before the intervention to $5.36,4.29$ and 5.35 servings in the first, second and third months after the start of intervention, respectively.

\section{Anthropometric assessment}

In Table 3, a comparison between the values of anthropometric indices in the two groups was made separated by time. Based on the results of covariance analysis test and by adjusting the effect of base values, a significant difference between the mean changes in BMI $(P=0.035)$ and BFM $(P=0.050)$ of the intervention and control groups were observed in a way that the decrease in BMI and BFM in the intervention group was more than that in the control group. Nevertheless, no significant statistical differences were observed between the two groups in terms of changes in weight, SMM, PBF, WHR and VFA.

\section{Score analysis of premenstrual symptoms}

In this study, a comparison was made between the two groups of intervention and control in PMS scores over time. The repeated-measures analysis test model 2 (by adjusting the effect of all confounding factors) showed that the interaction between 
Table 2. Comparing the daily physical activity, food and nutrient intake levels in nurses with premenstrual syndrome receiving diets rich in whole grains or usual diet over 3 months (Mean values and standard deviations)

\begin{tabular}{|c|c|c|c|c|c|c|c|c|c|c|c|c|c|c|c|c|c|c|c|}
\hline \multirow[b]{3}{*}{ Variables } & \multicolumn{8}{|c|}{ Rich in whole grain group ( $n$ 38) } & \multicolumn{8}{|c|}{ Usual diet group $(n 38)$} & \multirow[b]{3}{*}{$P_{\text {time }}$} & \multirow[b]{3}{*}{$P_{\text {group }}$} & \multirow[b]{3}{*}{$P_{\text {group } \times \text { time }}$} \\
\hline & \multicolumn{2}{|c|}{ Study onset } & \multicolumn{2}{|c|}{$\begin{array}{l}\text { End of the first } \\
\text { month }\end{array}$} & \multicolumn{2}{|c|}{$\begin{array}{c}\text { End of the } \\
\text { second month }\end{array}$} & \multicolumn{2}{|c|}{$\begin{array}{l}\text { End of the third } \\
\text { month }\end{array}$} & \multicolumn{2}{|c|}{ Study onset } & \multicolumn{2}{|c|}{$\begin{array}{l}\text { End of the third } \\
\text { month }\end{array}$} & \multicolumn{2}{|c|}{$\begin{array}{l}\text { End of the } \\
\text { second month }\end{array}$} & \multicolumn{2}{|c|}{$\begin{array}{l}\text { End of the first } \\
\text { month }\end{array}$} & & & \\
\hline & Mean & SD & Mean & SD & Mean & SD & Mean & SD & Mean & SD & Mean & SD & Mean & SD & Mean & SD & & & \\
\hline $\begin{array}{l}\text { Physical activities } \\
\text { (MET/h) }\end{array}$ & 21.4 & $4 \cdot 2$ & $21 \cdot 7$ & 4.0 & $21 \cdot 6$ & $4 \cdot 2$ & $22 \cdot 0$ & 3.9 & $20 \cdot 9$ & 4.9 & $20 \cdot 3$ & 4.8 & $20 \cdot 7$ & $4 \cdot 7$ & $20 \cdot 6$ & $5 \cdot 6$ & 0.42 & 0.002 & 0.57 \\
\hline Energy (kJ) & 7969.7 & 2076.5 & 8423.2 & $2045 \cdot 1$ & $7915 \cdot 7$ & $1654 \cdot 3$ & 8270.9 & $1421 \cdot 7$ & 7999.8 & 2307.5 & $7686 \cdot 0$ & 2102.5 & $7387 \cdot 3$ & 1828.0 & 7491.4 & 1758.9 & 0.03 & 0.002 & 0.67 \\
\hline Protein (g) & $70 \cdot 0$ & $21 \cdot 6$ & $78 \cdot 8$ & $22 \cdot 1$ & 71.7 & $16 \cdot 9$ & $75 \cdot 9$ & $15 \cdot 6$ & 71.0 & 21.8 & $70 \cdot 0$ & $22 \cdot 7$ & 67.5 & $20 \cdot 6$ & $62 \cdot 1$ & $17 \cdot 8$ & 0.06 & 0.001 & 0.09 \\
\hline Fat $(\mathrm{g})$ & $67 \cdot 1$ & 23.5 & 64.3 & $18 \cdot 7$ & $59 \cdot 3$ & $16 \cdot 5$ & 62.5 & $15 \cdot 6$ & $69 \cdot 4$ & 23.4 & 68.2 & 21.3 & 65.4 & 20.5 & 65.4 & $17 \cdot 3$ & 0.23 & 0.19 & 0.78 \\
\hline Carbohydrate (g) & 262.5 & 73.9 & $292 \cdot 6$ & 80.8 & $280 \cdot 0$ & $62 \cdot 9$ & 292.4 & $55 \cdot 0$ & 257.7 & 81.4 & $239 \cdot 3$ & $80 \cdot 0$ & $232 \cdot 1$ & 58.8 & $243 \cdot 2$ & $75 \cdot 6$ & 0.11 & $<0.001$ & 0.94 \\
\hline $\mathrm{Fe}(\mathrm{mg})$ & $13 \cdot 5$ & 3.7 & $15 \cdot 8$ & 4.2 & $15 \cdot 0$ & 3.0 & $15 \cdot 3$ & $3 \cdot 1$ & $12 \cdot 7$ & 3.9 & $12 \cdot 0$ & $3 \cdot 0$ & $11 \cdot 3$ & $2 \cdot 8$ & $11 \cdot 1$ & $2 \cdot 9$ & 0.58 & $<0.001$ & 0.72 \\
\hline $\mathrm{Mg}(\mathrm{mg})$ & $329 \cdot 3$ & $128 \cdot 3$ & 433.0 & 117.4 & $411 \cdot 1$ & 98.0 & $407 \cdot 8$ & 90.5 & $295 \cdot 8$ & 135.6 & 263.9 & 90.3 & $270 \cdot 0$ & $101 \cdot 3$ & 251.4 & $100 \cdot 8$ & 0.53 & $<0.001$ & 0.47 \\
\hline $\mathrm{Zn}$ (mg) & 8.9 & 2.6 & 11.6 & 3.1 & 10.8 & $2 \cdot 7$ & $11 \cdot 2$ & $2 \cdot 2$ & 8.9 & 2.7 & 8.8 & 3.1 & $8 \cdot 2$ & 2.7 & 7.9 & 2.4 & 0.30 & $<0.001$ & 0.43 \\
\hline $\mathrm{Mn}(\mathrm{mg})$ & 5.8 & $2 \cdot 4$ & 9.6 & 3.0 & $9 \cdot 1$ & 2.5 & 8.7 & $2 \cdot 7$ & $5 \cdot 7$ & 3.8 & 4.6 & $2 \cdot 0$ & $4 \cdot 7$ & $2 \cdot 0$ & 4.4 & $2 \cdot 6$ & 0.20 & $<0.001$ & 0.51 \\
\hline Vitamin E (mg) & $17 \cdot 7$ & $12 \cdot 2$ & 19.5 & 7.9 & $19 \cdot 0$ & $7 \cdot 2$ & $18 \cdot 0$ & 4.8 & 14.9 & $14 \cdot 8$ & $13 \cdot 0$ & 9.8 & $13 \cdot 6$ & 12.5 & $14 \cdot 3$ & 11.5 & 0.45 & 0.002 & 0.31 \\
\hline Thiamin (mg) & $1 \cdot 7$ & 0.6 & 1.7 & 0.5 & 1.6 & 0.4 & 1.6 & 0.3 & 1.6 & 0.8 & 1.5 & 0.5 & 1.4 & 0.6 & 1.4 & 0.5 & 0.50 & 0.004 & 0.78 \\
\hline Niacin $(\mathrm{mg})$ & 20.5 & 8.0 & 24.9 & 7.9 & 22.4 & 5.8 & $23 \cdot 7$ & $6 \cdot 3$ & 21.8 & 7.5 & 20.2 & 7.3 & $21 \cdot 2$ & $6 \cdot 7$ & $18 \cdot 7$ & $6 \cdot 7$ & 0.04 & $<0.001$ & 0.05 \\
\hline Folate $(\mu \mathrm{g})$ & 337.5 & 117.9 & 311.7 & $103 \cdot 4$ & $305 \cdot 3$ & 80.6 & 303.9 & $92 \cdot 1$ & 289.7 & $122 \cdot 6$ & 265.5 & $96 \cdot 4$ & $252 \cdot 0$ & $103 \cdot 4$ & 266.5 & $108 \cdot 8$ & 0.97 & 0.07 & 0.80 \\
\hline $\begin{array}{l}\text { Pantothenic acid } \\
\text { (mg) }\end{array}$ & 4.7 & 1.5 & $5 \cdot 4$ & 1.4 & $5 \cdot 3$ & $1 \cdot 3$ & $5 \cdot 4$ & $1 \cdot 0$ & 4.7 & 1.4 & 4.5 & 1.5 & 4.5 & $1 \cdot 3$ & $4 \cdot 3$ & $1 \cdot 2$ & 0.03 & $<0.001$ & 0.54 \\
\hline Vitamin K $(\mu \mathrm{g})$ & 94.7 & 57.9 & $137 \cdot 2$ & $73 \cdot 3$ & $146 \cdot 1$ & $70 \cdot 6$ & $145 \cdot 2$ & $80 \cdot 7$ & 79.9 & $42 \cdot 4$ & 80.7 & 59.5 & 75.5 & 35.9 & 84.2 & $54 \cdot 7$ & 0.64 & $<0.001$ & 0.81 \\
\hline Soluble fibre (g) & 0.5 & 0.4 & 0.4 & 0.3 & 0.5 & 0.3 & 0.6 & 0.5 & 0.5 & 0.4 & 0.5 & 0.3 & 0.4 & 0.3 & 0.5 & 0.4 & $0 \cdot 10$ & 0.69 & 0.14 \\
\hline Crude fibre $(\mathrm{g})$ & 4.9 & $2 \cdot 0$ & $7 \cdot 3$ & 2.6 & $7 \cdot 8$ & 2.4 & 8.2 & 1.9 & 4.7 & 1.9 & 4.1 & 1.8 & 4.0 & 1.3 & 4.9 & $2 \cdot 1$ & 0.001 & $<0.001$ & 0.56 \\
\hline Tryptophan (mg) & 631.7 & $209 \cdot 2$ & 918.9 & 332.9 & $845 \cdot 7$ & $215 \cdot 1$ & $856 \cdot 6$ & 198.4 & 711.3 & 249.1 & $684 \cdot 1$ & 242.5 & $687 \cdot 3$ & $242 \cdot 1$ & 595.4 & 205.0 & 0.04 & $<0.001$ & 0.17 \\
\hline $\mathrm{Ca}(\mathrm{mg})$ & $645 \cdot 2$ & 213.9 & 606.5 & 235.8 & $576 \cdot 2$ & 262.9 & 598.6 & $212 \cdot 2$ & $635 \cdot 1$ & $227 \cdot 3$ & $659 \cdot 3$ & $356 \cdot 2$ & 578.3 & $267 \cdot 10$ & 607.9 & 258.5 & 0.23 & 0.47 & 0.67 \\
\hline$P(\mathrm{mg})$ & 1147.9 & 328.8 & $1408 \cdot 6$ & $403 \cdot 6$ & $1326 \cdot 3$ & $340 \cdot 3$ & 1333.9 & 285.8 & $1099 \cdot 3$ & $398 \cdot 2$ & $1009 \cdot 0$ & $374 \cdot 8$ & $1017 \cdot 1$ & 337.0 & $963 \cdot 7$ & 310.5 & 0.49 & $<0.001$ & 0.51 \\
\hline $\mathrm{Cu}(\mathrm{mg})$ & 1.6 & 0.9 & 1.6 & 0.6 & 1.6 & 0.5 & 1.6 & 0.4 & 1.4 & 0.6 & 1.3 & 0.7 & 1.2 & 0.5 & 1.3 & 0.6 & 0.81 & 0.007 & 0.88 \\
\hline Se (mg) & 0.05 & 0.03 & 0.07 & 0.03 & 0.06 & 0.03 & 0.07 & 0.03 & 0.05 & 0.03 & 0.08 & 0.22 & 0.05 & 0.03 & 0.04 & 0.02 & 0.23 & 0.42 & 0.44 \\
\hline $\mathrm{Cr}(\mathrm{mg})$ & 0.03 & 0.02 & 0.04 & 0.05 & 0.03 & 0.03 & 0.03 & 0.03 & 0.03 & 0.02 & 0.03 & 0.02 & 0.03 & 0.02 & 0.03 & 0.02 & 0.63 & 0.46 & 0.57 \\
\hline Mo $(\mu \mathrm{g})$ & $28 \cdot 2$ & 33.8 & $25 \cdot 6$ & 21.4 & $27 \cdot 2$ & 23.4 & 24.9 & $24 \cdot 3$ & 34.5 & 34.2 & 34.7 & 29.9 & $35 \cdot 7$ & $34 \cdot 3$ & 21.9 & $16 \cdot 7$ & 0.59 & 0.33 & 0.27 \\
\hline Riboflavin (mg) & 1.6 & 0.7 & 1.6 & 0.4 & 1.5 & 0.4 & 1.6 & 0.4 & 1.5 & 0.4 & 1.5 & 0.6 & 1.3 & 0.4 & 1.4 & 0.4 & 0.49 & 0.11 & 0.29 \\
\hline Pyridoxine (mg) & 1.8 & $1 \cdot 1$ & 1.9 & 0.7 & 1.9 & 0.5 & 1.9 & 0.6 & 1.7 & 0.7 & 1.6 & 0.6 & 1.6 & 0.6 & 1.4 & 0.5 & 0.73 & 0.15 & 0.001 \\
\hline Cobalamin $(\mu \mathrm{g})$ & $2 \cdot 8$ & $2 \cdot 0$ & $2 \cdot 9$ & $3 \cdot 1$ & 2.5 & $2 \cdot 4$ & 3.0 & $3 \cdot 1$ & $2 \cdot 9$ & $2 \cdot 0$ & 4.0 & $5 \cdot 1$ & $2 \cdot 8$ & $2 \cdot 7$ & 3.0 & 4.0 & 0.44 & 0.49 & 0.36 \\
\hline Biotin $(\mu \mathrm{g})$ & 11.3 & $6 \cdot 2$ & $16 \cdot 7$ & $6 \cdot 6$ & $17 \cdot 2$ & $6 \cdot 2$ & $18 \cdot 1$ & $7 \cdot 0$ & $12 \cdot 3$ & 7.5 & $11 \cdot 1$ & $7 \cdot 0$ & 11.3 & $6 \cdot 1$ & $11 \cdot 2$ & $6 \cdot 7$ & 0.04 & $<0.001$ & 0.75 \\
\hline Vitamin D $(\mu \mathrm{g})$ & $1 \cdot 1$ & 1.0 & 1.2 & 1.0 & 1.3 & 1.4 & 1.4 & 1.2 & $1 \cdot 1$ & $1 \cdot 1$ & 1.0 & 1.0 & 1.2 & 1.2 & $1 \cdot 1$ & 1.2 & 0.90 & 0.32 & 0.57 \\
\hline Dietary fibre (g) & $17 \cdot 2$ & $6 \cdot 0$ & 31.8 & $10 \cdot 2$ & 31.6 & 7.3 & $32 \cdot 0$ & 6.9 & $15 \cdot 0$ & $7 \cdot 2$ & $13 \cdot 7$ & 5.8 & $12 \cdot 4$ & 4.3 & 14.9 & $6 \cdot 1$ & 0.11 & $<0.001$ & 0.57 \\
\hline $\begin{array}{l}\text { Milk and dairy } \\
\text { products } \\
\text { (servings) }\end{array}$ & 0.8 & 0.5 & 0.8 & 0.7 & 0.7 & $0 \cdot 7$ & 0.8 & 0.6 & 0.8 & 0.6 & $1 \cdot 0$ & $1 \cdot 1$ & 0.8 & 0.6 & 0.8 & 0.9 & 0.39 & 0.79 & 0.75 \\
\hline $\begin{array}{l}\text { Vegetables } \\
\text { (servings) }\end{array}$ & $2 \cdot 4$ & 1.5 & $2 \cdot 5$ & 1.4 & $2 \cdot 2$ & 1.2 & $2 \cdot 4$ & 1.0 & $2 \cdot 1$ & 1.3 & $2 \cdot 2$ & $1 \cdot 2$ & $2 \cdot 0$ & $1 \cdot 2$ & $2 \cdot 1$ & 1.2 & 0.17 & 0.41 & 0.92 \\
\hline Fruits (servings) & 2.5 & 1.8 & 1.9 & 1.4 & $2 \cdot 7$ & $1 \cdot 7$ & 3.3 & $2 \cdot 1$ & 2.4 & 1.8 & 2.0 & 1.6 & $2 \cdot 0$ & 1.3 & 3.3 & $2 \cdot 8$ & 0.02 & 0.52 & 0.28 \\
\hline Cereals (servings) & 12.5 & $4 \cdot 1$ & $15 \cdot 5$ & 4.4 & $13 \cdot 7$ & 3.4 & 13.7 & 3.5 & $12 \cdot 4$ & 4.6 & 11.4 & 3.8 & $10 \cdot 6$ & $2 \cdot 9$ & $10 \cdot 6$ & 3.6 & 0.50 & $<0.001$ & 0.38 \\
\hline Meat (servings) & $5 \cdot 1$ & $2 \cdot 3$ & $5 \cdot 0$ & $2 \cdot 1$ & 4.4 & 1.7 & 4.8 & 1.5 & $5 \cdot 3$ & $2 \cdot 2$ & $5 \cdot 1$ & $2 \cdot 4$ & $5 \cdot 1$ & 2.5 & 4.2 & $2 \cdot 3$ & 0.62 & 0.94 & 0.07 \\
\hline Fat (servings) & 11.6 & 4.7 & $10 \cdot 7$ & 3.4 & 9.9 & 3.1 & $10 \cdot 1$ & 2.9 & 11.3 & 4.6 & 11.0 & 4.1 & $10 \cdot 9$ & 3.9 & 11.3 & 3.4 & 0.57 & 0.05 & 0.52 \\
\hline
\end{tabular}

${ }^{*} P$ values represent the effect of time, group and time $\times$ group interaction computed by analysis of general linear model ANOVA for repeated measurements. Whole grain group. 
Table 3. Comapring the anthropometric profiles in nurses with premenstrual syndrome following diet rich in whole grains or usual diet over 3 months (Mean values and standard deviations)

\begin{tabular}{|c|c|c|c|c|c|c|c|c|c|c|c|c|c|c|c|}
\hline \multirow[b]{3}{*}{ Variables } & \multicolumn{6}{|c|}{ Rich in whole grain group ( $n 38)$} & \multirow[b]{3}{*}{$P^{\star}$} & \multicolumn{6}{|c|}{ Usual diet group ( $n$ 38) } & \multirow[b]{3}{*}{$P \dagger$} & \multirow[b]{3}{*}{$P \neq$} \\
\hline & \multicolumn{2}{|c|}{ Study onset } & \multicolumn{2}{|c|}{ Study outset } & \multicolumn{2}{|c|}{ Amount of change } & & \multicolumn{2}{|c|}{ Study onset } & \multicolumn{2}{|c|}{ Study outset } & \multicolumn{2}{|c|}{ Amount of change } & & \\
\hline & Mean & SD & Mean & SD & Mean & SD & & Mean & SD & Mean & $\mathrm{SD}$ & Mean & SD & & \\
\hline Weight (kg) & $64 \cdot 2$ & $10 \cdot 2$ & $63 \cdot 7$ & 9.9 & -0.4 & $2 \cdot 5$ & 0.32 & $63 \cdot 1$ & $10 \cdot 3$ & $63 \cdot 3$ & $10 \cdot 8$ & 0.2 & 1.6 & 0.52 & 0.25 \\
\hline BMI $\left(\mathrm{kg} / \mathrm{m}^{2}\right)$ & $25 \cdot 6$ & 3.8 & $25 \cdot 3$ & 3.7 & -0.2 & 0.7 & 0.03 & 24.9 & 4.2 & 24.9 & 4.4 & 0.07 & 0.6 & 0.44 & 0.03 \\
\hline BFM (kg) & $24 \cdot 1$ & $6 \cdot 6$ & $23 \cdot 1$ & $6 \cdot 3$ & -0.1 & $1 \cdot 3$ & $<0.001$ & $23 \cdot 4$ & $7 \cdot 12$ & $23 \cdot 1$ & 7.37 & -0.4 & 1.25 & 0.08 & 0.05 \\
\hline SMM (kg) & 21.6 & $2 \cdot 8$ & $21 \cdot 8$ & $2 \cdot 8$ & 0.2 & 0.7 & 0.14 & 21.4 & $2 \cdot 6$ & 22.00 & $2 \cdot 8$ & 0.6 & 1.8 & 0.05 & 0.19 \\
\hline PBF (\%) & $37 \cdot 0$ & 5.4 & 35.5 & $5 \cdot 1$ & -1.5 & 2.9 & 0.003 & $35 \cdot 7$ & $7 \cdot 0$ & $35 \cdot 6$ & $6 \cdot 0$ & 0.00 & 3.9 & 0.99 & 0.11 \\
\hline WHR & 0.9 & 0.05 & 0.9 & 0.04 & -0.01 & 0.02 & 0.005 & 0.9 & 0.05 & 0.9 & 0.04 & 0.00 & 0.03 & 0.36 & 0.16 \\
\hline VFA $\left(\mathrm{cm}^{2}\right)$ & $116 \cdot 4$ & 38.4 & $110 \cdot 7$ & $37 \cdot 1$ & $-5 \cdot 7$ & 11.2 & 0.004 & $112 \cdot 8$ & $40 \cdot 1$ & $109 \cdot 2$ & 39.4 & $-3 \cdot 6$ & 7.04 & 0.003 & 0.39 \\
\hline
\end{tabular}

BFM, body fat mass; SMM, skeletal muscle mass; PBF, percentage of body fat; WHR, waist:hip ratio; VFA, visceral fat area.

* Comparison between before and after values in the whole grain group applying paired $t$ test.

$\dagger$ Comparison between before and after values in the usual diet group applying paired $t$ test.

$\ddagger$ Comparison between change values in the two groups of whole grain and usual diet groups by adjusting the base values applying co-variance analysis.

the time factor and experimental group was significant in mean scores of general, mood, physical and behavioural symptoms of PMS. In the intervention group, in comparison with the control group, the scores of general, mood, physical and behavioural symptoms were reduced significantly $(P<0 \cdot 001, \quad P=0 \cdot 01$, $P<0.001$ and $P=0.003)$. Further details are available in the Fig. 2 and online Supplementary Table S1.

\section{Discussion}

To the best of our knowledge, this is the first study investigating the effect of diets rich in whole grains on the intensity of PMS symptoms. In this study, we found that increasing the consumption of whole grains in individuals with PMS caused a decrease in the intensity of physical, mood and behavioural symptoms. Our results revealed there was no difference between the intervention and control groups during the study regarding the consumption of food groups except for cereals, which significantly increased in the intervention group. The intervention group increased their daily whole grain intake nearly four servings, about half of it was consumed instead of refined grains and other half was consumed extra than baseline cereal intake. Therefore, it caused increased intake of energy and macronutrients. Since we controlled the effect of energy and macronutrient intake, the study results can be assumed due to replacement of refined grains with whole grains. Increasing the intake of whole grains in the intervention group is accompanied by an increase in some micronutrients and vitamins such as $\mathrm{Mg}, \mathrm{Zn}, \mathrm{Mn}$, vitamin $\mathrm{E}$, thiamin, $\mathrm{Cu}$, pyridoxine and biotin whose beneficial effects on controlling PMS symptoms are observed in previous studies. Due to their effect on neurotransmitter metabolism, vitamin B plays an important role in relation to this syndrome. This is because disorders and abnormalities of neurotransmitters, such as serotonin, dopamine, and $\gamma$-aminobutyric acid (GABA), are among the important aetiologies associated with $\mathrm{PMS}^{(28,29)}$. Thiamin is essential for GABA precursor metabolism; vitamin $\mathrm{B}_{6}$, vitamin $\mathrm{B}_{12}$ and folate are essential for the formation of $S$-adenosyl-methionine; and tetrahydrobiopterin is essential for serotonin and dopamine metabolism $^{(30,31)}$. Furthermore, riboflavin is required in the production of pyridoxal phosphate, and pyridoxal phosphate and niacin are required in the production of serotonin from tryptophan $^{(32)}$.

In the study conducted by Chocano-Bedoya et $a l^{(19)}$, an inverse association was observed between dietary thiamin and riboflavin and the risk of PMS. These results were obtained with a diet that contained thiamin and riboflavin higher than RDA $(1.1 \mathrm{mg} / \mathrm{d})$, in such a way that women receiving a daily dose of $1.9 \mathrm{mg}$ of thiamin from their diets had a $25 \%$ lower risk of PMS than women receiving a daily dose of $1.2 \mathrm{mg}$. It is interesting that this level of intake is supplied with the consumption of two to three servings of thiamine-rich foods, such as whole grains and beans. Moreover, women receiving a daily dose of $2.5 \mathrm{mg}$ of riboflavin, as opposed to receiving $1.4 \mathrm{mg}$ of it, were $35 \%$ less likely to developing PMS. This level of intake was supplied with $1-2$ servings/d of enriched grains ${ }^{(19)}$. Meanwhile, according to the National Food Consumption Survey, the total grain intake among Iranian people is much lower than that recommended by the US Food Department's pyramid (6-11 servings/ d), that is, $<2$ servings $/ \mathrm{d}^{(33)}$

The potential effects of vitamin supplements in the treatment of PMS have also been evaluated in previous studies. Although in the London et $a l .{ }^{(34)}$ study, the consumption of multivitaminmineral supplements including vitamins B, A, D, C and E as well as minerals such as $\mathrm{Mg}, \mathrm{Mn}, \mathrm{Fe}$ and $\mathrm{Cu}$ reduced the severity of PMS symptoms in the intervention group compared with that in the control group, based on the results of the study performed by Chocano-Bedoya et $a l{ }^{(19)}$, an increase in the intake of these vitamins through supplements was associated with an increase in the risk of incidence of PMS. Due to biological interaction between $\mathrm{B}$ vitamins, their concurrent consumption is important. This can be explained through an example: for pyridoxine hydrochloride to convert into its active form, that is pyridoxal phosphate, it requires riboflavin. Therefore, when used concurrently, there will not be a deficiency in $\mathrm{B}_{6}$ active level; and in this way, the supplement will have a better effect on the intensity of PMS symptoms ${ }^{(34)}$.

Consuming wheat germ extract as a food source rich in vitamins $\mathrm{B}, \mathrm{E}$ and $\mathrm{C}$, as well as minerals, such as $\mathrm{Zn}, \mathrm{Mg}, \mathrm{Ca}$, caused a significant reduction in the three categories of general, physical and psychological symptoms of PMS in the wheat germ 
(a)

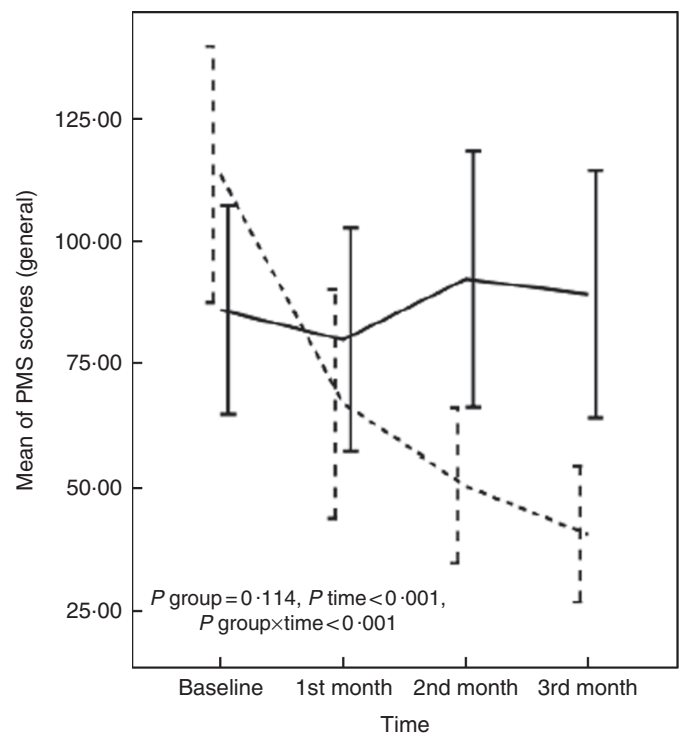

(c)

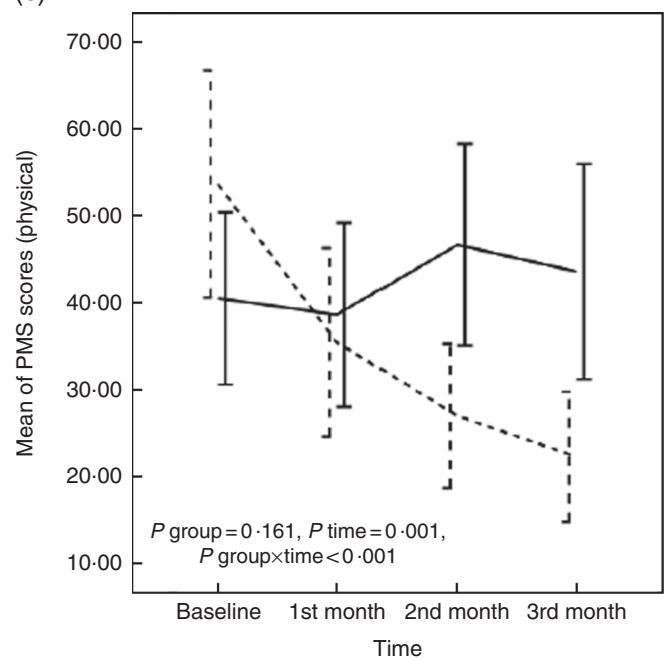

(b)

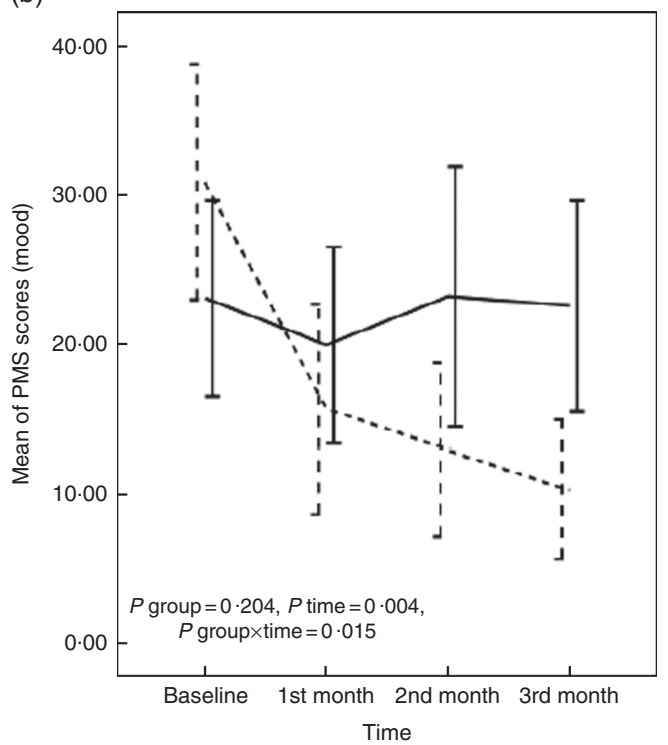

(d)

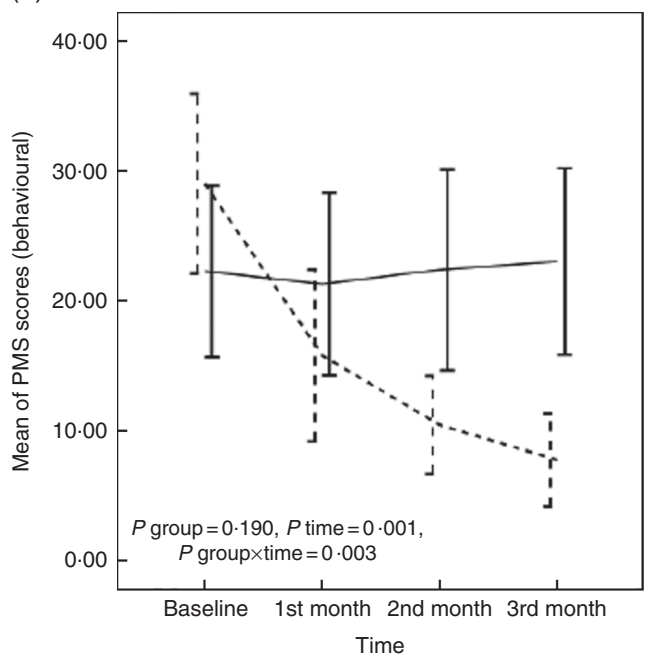

Fig. 2. Changes in general (a), mood (b), physical (c) and behavioural (d) scores of premenstrual syndrome (PMS) in nurses with PMS who received diet enriched with whole grains or usual diet for 3 months. Values are means, with $95 \%$ confidence intervals represented by vertical bars. $P$ values represent the effect of time, group and time $\times$ group interaction computed by analysis of general linear model ANOVA for repeated measurements after adjusting for baseline value of the outcome, marital status; age; duration of a menstrual cycle; the mean change of physical activity; intake of energy, protein, carbohydrate, and fat across different times during the study; and changes in BMI, body fat mass, skeletal muscle mass, percentage of body fat and waist:hip ratio. ---- , Intervention group; - , Control group.

group $^{(20)}$. Diets with low Mn levels $(1 \mathrm{mg} / \mathrm{d})$, as opposed to diets with higher Mn levels $(5-6 \mathrm{mg} / \mathrm{d})$, were also associated with an increase in mood symptoms and pain in the premenstrual phase of menstrual cycle ${ }^{(35)}$. Some other studies have reported the beneficial effects of $\mathrm{Zn}, \mathrm{Mg}, \mathrm{Ca}$ and some other micronutrients in relief of PMS symptoms as well ${ }^{(17,35-37)}$.

Whole grains are food sources rich in soluble and insoluble fibres such as inulin, $\beta$-glucan and resistant starch. Following a diet rich in whole grains was associated with an increase in receiving dietary fibres. In the study conducted by Houghton et $a l{ }^{(38)}$ on the relationship between dietary fibre and risk of PMS, it was observed that the daily consumption of dietary fibres and carbohydrates, except for maltose, had no effect on
PMS development. Meanwhile, in a cross-sectional study carried out by Nagata et al. ${ }^{(39)}$, after adjusting the age, age at menarche, total energy intake and smoking, an inverse association was observed between menstrual pain and dietary fibre in people with dysmenorrhea.

In general, in this study, replacing refined grains with whole grains, which have higher nutritional values, was associated with the relief of PMS symptoms.

The greatest advantage of this study is the strong effect of whole grain consumption on reducing the PMS scores. Of other advantages, one can refer to the 5-month follow-up of the participants in dietary patterns and lifestyle 2 months before and 3 months after the start of intervention. One limitation of 
the study was it being open-label and the possibility of placebo effect due to its nature and impossibility of blinding; although in the study conducted by Freeman \& Rickels ${ }^{(40)}$, to evaluate the effect of placebo on the treatment of PMS, the majority of participants reported only partial improvement or no improvement at all. The second limitation was its high dropout rate of participants during the study due to high workload and subsequent loss of their data and not using intention-to-treat analysis. To overcome this problem, two models of adjusting covariates, especially baseline values in statistical analysis were used. In addition, dropout of non-compliant patients could help to get definite results. Not including the nurses from hospitals' operating rooms in the study due to the difficulty in entering those sections was among other limitations of the study. Although we lost data on nurses with high stress jobs, we eliminated the effect of stress on PMS.

\section{Conclusion}

PMS affects the normal function of women in the workplace, family and even sexual relationship. Pharmaceutical treatments, especially with SSRI, which are at the head of the treatment, are associated with some side effects, and women with less severe symptoms are less likely to accept this treatment. To the best of our knowledge, no randomised controlled trials had been carried out until now to investigate the effect of diets enriched with whole grains on PMS symptoms. In this paper, we showed that following a diet rich in whole grains for 3 months led to statistically and clinically significant improvements in the severity of general, physical, mood and behavioural symptoms of PMS.

\section{Acknowledgements}

The authors would like to express their deep appreciation to all the nurses whom despite their highly demanding jobs and hard working conditions cooperated with them very well. The authors would also like to thank the company producing organic products under the Biotarla brand, which provided whole-wheat bread to the participants. Furthermore, the authors are grateful to Ms Shirin Ebrahimkhani, Ms Masoomeh Dorosti and Ms Kiana Sadeghi for all their kind assistance in carrying out the present study.

The Urmia University of Medical Sciences supported funding sources of this study.

The authors' responsibilities are as follows: M. A. and M. E. conceived and designed the study and analysed the data; S. G. provided material and technical support; M. E. wrote the manuscript; M. A. critically revised the manuscript for important intellectual content and M. A. had primary responsibility. All authors read and approved the final manuscript.

The lead author affirms that this manuscript is an honest, accurate and transparent account of the study being reported. The reporting of this work is compliant with CONSORT guidelines. The lead author affirms that no important aspects of the study have been omitted and that any discrepancies from the study as planned have been explained.

M. E., S. G. and M. A. have no conflicts of interest.

\section{Supplementary material}

For supplementary material/s referred to in this article, please visit https://doi.org/10.1017/S0007114519000333

\section{References}

1. Steiner M \& Born L (2000) Diagnosis and treatment of premenstrual dysphoric disorder: an update. Int Clin Psychopharmacol 15, 5-17.

2. Singh BB, Berman BM, Simpson RL, et al. (1998) Incidence of premenstrual syndrome and remedy usage: a national probability sample study. Altern Ther Health Med 4, 75-79.

3. Dickerson LM, Mazyck PJ \& Hunter MH (2003) Premenstrual syndrome. Am Fam Physician 67, 1743-1752.

4. Halbreich U, Borenstein J, Pearlstein T, et al. (2003) The prevalence, impairment, impact, and burden of premenstrual dysphoric disorder (PMS/PMDD). Psychoneuroendocrinology 28, Suppl. 3, 1-23.

5. Ranjbaran M, Omani Samani R, Almasi-Hashiani A, et al. (2017) Prevalence of premenstrual syndrome in Iran: a systematic review and meta-analysis. Int J Reprod Biomed 15, 679-686.

6. Namavar Jahromi B, Pakmehr S \& Hagh-Shenas H (2011) Work stress, premenstrual syndrome and dysphoric disorder: are there any associations? Iran Red Crescent Med J 13, 199-202.

7. Wyatt KM, Dimmock PW \& O'Brien PM (2007) Selective serotonin reuptake inhibitors for premenstrual syndrome. Cochrane Database Syst Rev, issue 4, CD001396.

8. Saeedian Kia A, Amani R \& Cheraghian B (2015) The association between the risk of premenstrual syndrome and vitamin $\mathrm{D}$, calcium, and magnesium status among university students: a case-control study. Health Promot Perspect 5, 225-230.

9. Ferruzzi MG, Jonnalagadda SS, Liu S, et al. (2014) Developing a standard definition of whole-grain foods for dietary recommendations: summary report of a multidisciplinary expert roundtable discussion. Adv Nutr 5, 164-176.

10. Bellisle F, Hebel P, Colin J, et al. (2014) Consumption of whole grains in French children, adolescents and adults. $\mathrm{BrJ}$ Nutr 112, 1674-1684.

11. Mann KD, Pearce MS, McKevith B, et al. (2015) Whole grain intake and its association with intakes of other foods, nutrients and markers of health in the National Diet and Nutrition Survey rolling programme 2008-11. BrJ Nutr $\mathbf{1 1 3}$, 595-602.

12. Mann KD, Pearce MS, McKevith B, et al. (2015) Low whole grain intake in the UK: results from the National Diet and Nutrition Survey rolling programme 2008-11. Br J Nutr 113, 1643-1651.

13. O'Neil CE, Nicklas TA, Zanovec M, et al. (2010) Whole-grain consumption is associated with diet quality and nutrient intake in adults: the National Health and Nutrition Examination Survey, 1999-2004. J Am Diet Assoc 110, 1461-1468.

14. Abdollahifard S, Rahmanian Koshkaki A \& Moazamiyanfar R (2014) The effects of vitamin $B_{1}$ on ameliorating the premenstrual syndrome symptoms. Global J Health Sci 6, 144-153.

15. Bertone-Johnson ER, Hankinson SE, Bendich A, et al. (2005) Calcium and vitamin D intake and risk of incident premenstrual syndrome. Arch Intern Med 165, 1246-1252.

16. Ebrahimi E, Khayati Motlagh S, Nemati S, et al. (2012) Effects of magnesium and vitamin $\mathrm{B}_{6}$ on the severity of premenstrual syndrome symptoms. J Caring Sci 1, 183-189. 
17. Siahbazi S, Behboudi-Gandevani S, Moghaddam-Banaem L, et al. (2017) Effect of zinc sulfate supplementation on premenstrual syndrome and health-related quality of life: clinical randomized controlled trial. J Obstet Gynaecol Res 43, 887-894.

18. Thys-Jacobs S, Starkey P, Bernstein D, et al. (1998) Calcium carbonate and the premenstrual syndrome: effects on premenstrual and menstrual symptoms. Premenstrual Syndrome Study Group. Am J Obstet Gynecol 179, 444-452.

19. Chocano-Bedoya PO, Manson JE, Hankinson SE, et al. (2011) Dietary B vitamin intake and incident premenstrual syndrome. Am J Clin Nutr 93, 1080-1086.

20. Ataollahi M, Akbari SA, Mojab F, et al. (2015) The effect of wheat germ extract on premenstrual syndrome symptoms. Iran J Pharm Res 14, 159-166.

21. Farasati N, Siassi F, Koohdani F, et al. (2015) Western dietary pattern is related to premenstrual syndrome: a casecontrol study. Br J Nutr 114, 2016-2021.

22. Barnard ND, Scialli AR, Hurlock D, et al. (2000) Diet and sexhormone binding globulin, dysmenorrhea, and premenstrual symptoms. Obstet Gynecol 95, 240-250.

23. Bahreynian M \& Esmaillzadeh A (2012) Quantity and quality of carbohydrate intake in Iran: a target for nutritional intervention. Arch Iran Med 15, 948-949.

24. Ghassemzadeh H, Mojtabai R, Karamghadiri N, et al. (2005) Psychometric properties of a Persian-language version of the Beck Depression Inventory - second edition: BDI-II-PERSIAN. Depress Anxiety 21, 185-192.

25. American College of Obstetrics and Gynecology Practice Bulletin (2000) Clinical management guidelines for obstetricians-gynecologists. Am J Obstet Gynecol 95, 1-9.

26. Canning SE, Waterman MG, Simpson N, et al. (2012) Reliability and component structure of the modified Daily Symptom Report (DSR-20). J Affect Disord 136, 612-619.

27. Freeman EW (2003) Premenstrual syndrome and premenstrual dysphoric disorder: definitions and diagnosis. Psychoneuroendocrinology 28, 25-37.
28. Clare AW (1985) Premenstrual syndrome: single or multiplecauses? Can J Psychiatry 30, 474-482.

29. Rapkin AJ (1992) The role of serotonin in premenstrual syndrome. Clin Obstet Gynecol 35, 629-636.

30. Frankenburg FR (2007) The role of one-carbon metabolism in schizophrenia and depression. Harv Rev Psychiatry 15, 146-148.

31. Miller AL (2008) The methylation, neurotransmitter, and antioxidant connections between folate and depression. Altern Med Rev 13, 216-226.

32. Stipanuk MH (2006) Biochemical, physiological, and molecular aspects of human nutrition, 2nd edn. St Louis: Saunders Elsevier.

33. Esmaillzadeh A, Mirmiran P \& Azizi F (2005) Whole-grain consumption and the metabolic syndrome: a favorable association in Tehranian adults. Eur J Clin Nutr 59, 353-362.

34. London RS, Bradley L \& Chiamori NY (1991) Effect of a nutritional supplement on premenstrual symptomatology in women with premenstrual syndrome: a double-blind longitudinal study. J Am Coll Nutr 10, 494-499.

35. Penland JG \& Johnson PE (1993) Dietary calcium and manganese effects on menstrual cycle symptoms. Am J Obstet Gynecol 168, 1417-1423.

36. Thys-Jacobs S, Ceccarelli S, Bierman A, et al. (1989) Calcium supplementation in premenstrual syndrome: a randomized crossover trial. J Gen Intern Med 4, 183-189.

37. Walker AF, De Souza MC, Vickers MF, et al. (1998) Magnesium supplementation alleviates premenstrual symptoms of fluid retention. $J$ Womens Health 7, 1157-1165.

38. Houghton SC, Manson JE, Whitcomb BW, et al. (2018) Carbohydrate and fiber intake and the risk of premenstrual syndrome. Eur J Clin Nutr 72, 861-870.

39. Nagata C, Hirokawa K, Shimizu N, et al. (2005) Associations of menstrual pain with intakes of soy, fat and dietary fiber in Japanese women. Eur J Clin Nutr 59, 88-92.

40. Freeman EW \& Rickels K (1999) Characteristics of placebo responses in medical treatment of premenstrual syndrome. Am J Psychiatry 156, 1403-1408. 